\title{
PELATIHAN PEMBUATAN LAYOUT PCB \\ DENGAN DIP TRACE DAN DRY FILM PHOTORESIST \\ BAGI SMK MUHAMMADIYAH 2 SALAM MAGELANG
}

\author{
Denny Dermawan \\ Departemen Teknik Elektro \\ Sekolah Tinggi Teknologi Adisutjipto Yogyakarta \\ Jl. Janti Blok R Lanud Adisutjipto Yogyakarta \\ dennydermawanstta@gmail.com
}

\begin{abstract}
The desire of students of SMK Muhammadiyah 2 Salam Magelang to be able to make a printed circuit board is something that is very important to be welcomed and followed up wisely so that the desire of the students is not just a wishful dream but will be a reality. This activity is meant to be an effort not only to overcome difficulties at certain times (short-term activities), but is expected to be sustainable for the future (longer term). Looking at the fact, of course, should be strived to realize the handling of the problem at least for the near term. For that required activities that are practical and immediate benefits can be taken as the activity can be a short course or short training. To solve the problem, it is realized by holding a short course training course on PCB Layout Creation with DIP TRACE and Dry Film Photoresist technology followed by etching process, drilling and installation of components that will be useful for students who want to do the main final work related with the manufacture of tools hardware.
\end{abstract}

Keywords : Making PCB, DIP TRACE, Dry Photoresist film

\begin{abstract}
Abstrak
Keinginan siswa SMK Muhammadiyah 2 Salam Magelang untuk dapat membuat papan rangkaian tercetak merupakan sesuatu yang sangat penting untuk disambut dan ditindak lanjuti secara bijak sehingga keinginan siswa tersebut tidak hanya sekedar angan-angan namun akan dapat menjadi kenyataan. Kegiatan ini dimaksud tentunya merupakan upaya yang tidak hanya untuk mengatasi kesulitan pada waktu tertentu saja (kegiatan jangka pendek), melainkan diharapkan dapat berkelanjutan untuk masa masa yang akan datang (jangka waktu yang lebih panjang). Melihat kenyataan tersebut, tentunya harus diupayakan untuk mewujudkan penanganan masalah minimal untuk jangka waktu dekat. Untuk itu dibutuhkan kegiatan-kegiatan yang bersifat praktis dan segera dapat diambil manfaatnya adapun kegiatan tersebut dapat berupa kursus singkat ataupun pelatihan singkat. Untuk menyelesaikan masalah tersebut maka diwujudkan dengan mengadakan kegiatan berupa kursus / pelatihan singkat tentang Pembuatan Layout PCB dengan DIP TRACE dan teknologi Dry Film Photoresist yang dilanjutkan dengan proses etching, pengeboran dan pemasangan komponen yang nantinya akan berguna bagi siswa yang ingin melakukan karya akhir utamanya yang berkaitan dengan pembuatan alat/hardware.
\end{abstract}

Kata Kunci : Pembuatan PCB, DIP TRACE, Dry Film Photoresist 


\section{Latar Belakang Masalah}

Siswa SMK Muhammadiyah 2 Salam Magelang jurusan teknik Penerbangan terutama siswa tingkat akhir sering dihadapkan pada situasi harus membuat rangkaian perangkat keras yang notabene papan rangkaian tercetaknya tidak terdapat dipasaran, karena merupakan hasil kreasi siswa sendiri. Sehingga diperlukan kemampuan untuk dapat membuat PCB sendiri dan dibantu oleh perangkat lunak penggambar. Perangkat lunak yang digunakan sebagai media menggambar skematik rangkain dan pembuatan layout PCB banyak sekali jenisnya antara lain yaitu Protel Schematic Design for Windows, OrCAD, DIP TRACE, dan masih banyak lagi.

Kurangnya pengetahuan para siswa tentang teknik pembuatan PCB menggunakan komputer dan teknik transfer layout PCB ke papan PCB sangat dimungkinkan menjadi penyebab rendahnya motivasi siswa untuk mengambil tugas akhir berupa pembuatan alat/hardware. Untuk itu diperlukan semacam pelatihan untuk membuaka wawasan siswa tentang pembuatan PCB menggunakan komputer dan teknik transfer menggunakan Dry Film Photoresist.

\section{Metodologi Pelaksanaan} berikut

Metode pelaksanaan untuk mengatasi permasalahan prioritas Mitra adalah sebagai

a. Metode yang dipilih untuk meningkatkan kompetensi siswa bidang keahlian implementasi perangkat keras adalah dengan memberikan pelatihan dan pembekalan materi pelajaran perancangan PCB dengan menggunakan perangkat lunak DIP TRACE kepada siswa. Pelatihan dan pembekalan dilaksanakan di lokasi mitra selama 2 (dua) hari dengan materi mulai dari dasar-dasar perancangan perangkat keras, pembuatan layout PCB serta implementasinya.

b. Metode yang dipilih untuk mengatasi keterbatasan alat peraga pendidikan, khususnya bidang pembuatan $\mathrm{PCB}$, adalah antara lain dengan membuat parangkat keras lampu penyinar ultra violet.

\subsection{Prinsip Kerja Sistem}

Salah satu metode dalam membuat track PCB adalah dengan image photo transfer, dengan tehnik ini dapat menghasilkan jalur PCB yang maksimal dengan tingkat kesulitan yang cukup tinggi hingga $0,254 \mathrm{~mm}$. Bahan yang digunakan adalah Dry Film Photoresist (Photo Sensitive Film), dalam metode ini diperlukan film negatif (kebalikan dari yang biasa dipakai untuk sablon) sebagai artwork (sarana image transfer). Dry Film memiliki beberapa keunggulan diantaranya

$>$ Melekat kuat di PCB sehingga tidak mudah putus saat proses etching

$>$ Memilki ketelitian tinggi ( sampai dengan $+0,254 \mathrm{~mm}$ )

$>$ Contrast yang bagus

> Mudah distripping (dilunturkan)

Ada beberapa tahapan dalam membuat jalur PCB dengan menggunakan Dry Film Photoresist yaitu :

1. Pre-laminasi

2. Laminasi

3. Exposure (penyinaran)

4. Post exposure hold time (dibiarkan setelah di exposure)

5. Development (pengembangan) 

6. Pre-etch drying (pengeringan)
7. Etching,
8. Stripping (dilunturkan)
9. Finishing

\subsubsection{Pre Laminasi}

Pre-laminasi adalah proses perlakuan awal untuk PCB sebelum digunakan. Proses yang dilakukan pada pre-laminasi ini yaitu : membersihkan PCB yang akan digunakan dari kotoran, debu dan minyak. Pembersihan PCB dapat dilakukan dengan menggosok dengan amplas halus secara merta ke seluruh $\mathrm{PCB}$ atau kalau kotornya ringan dapat menggunakan stell wool untuk membersihkan PCB. PCB yang digosok dengan amplas halus diperlihatkan pada gambar 1 dan hasil dari PCB yang telah bersih diperlihatkan pada gambar 2 .

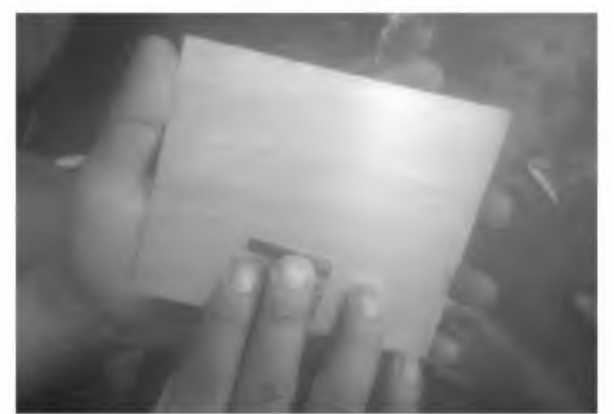

Gambar 1. PCB digosok dengan amplas halus

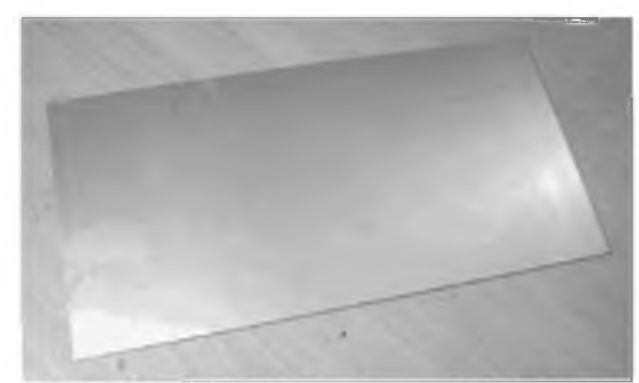

Gambar 2. PCB yang sudah bersih

\subsubsection{Laminasi}

Proses laminasi adalah proses penempelan dry film ke PCB. Dry Film Photeresist adalah plastik yang memiliki karaktristik seperti diperlihatkan pada gambar 3 .

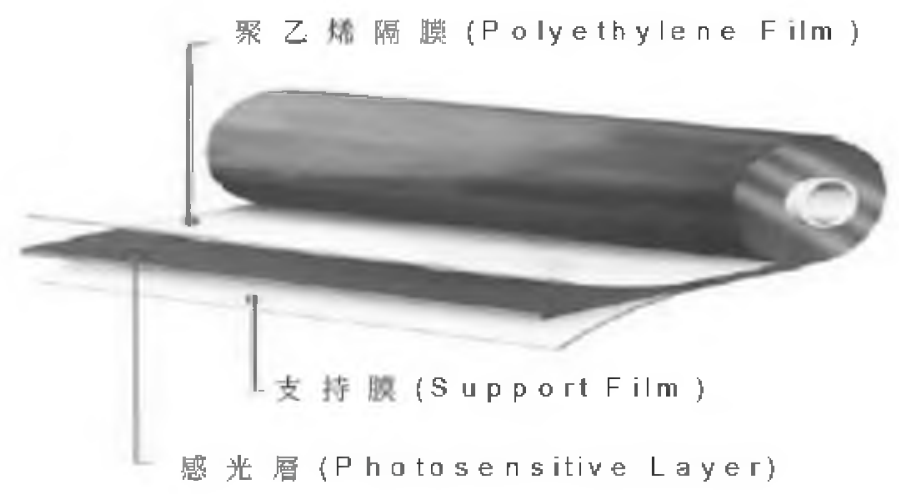

Gambar 3. Struktur Dry Film Photoresist 
Lapisan paling atas (top layer) terbuat dari bahan Polyethylene Film (PET) dengan ketebalan sekitar $25 \mu \mathrm{m}$. Plastik bagian atas ini terlihat bening. Lapisan bagian bawah adalah lapisan support atau protective yang terbuat dari bahan Polyester (PE) dengan ketebalan yang sama yaitu sekitar $25 \mu \mathrm{m}$. Plastik bagian bawah ini agak lebih buram dibanding plastik bagian atas. Lapisan tengah adalah lapisan photosensitive, ketebalannya tergantung pada aplikasi dan mempunyai rentang antara beberapa micron sampai dengan $150 \mu \mathrm{m}$. Bagian tengah adalah bagian photosensitive yang sangat peka terhadap sinar Ultra Violet (UV).

Pastikan yang dikupas pertama pada saat ditempel di pcb adalah lapisan bawah tidak boleh terbalik karena jalur sama sekali tidak akan terbentuk saat di developing sebab posisi Dry Film terbalik. Hal lain yang harus diperhatikan adalah tidak boleh terkena cahaya (UV).

Cara mengambil plastik bagian bawah dry film adalah dengan merekatkan isolasi kupas dari bagian ujung (pojok) agar lebih mudah, caranya lekatkan solasi di 2 sisi lalu tarik perlaha-lahan sampai plastik bagian bawahnya terkelupas.

Pada proses yang kedua yaitu proses laminasi, maka usahakan tempat yang dipakai untuk laminasi bersih dari debu dan kondisi ruangan cukup gelap seperti tempat afdruk foto, dalam proses laminasi Dry Film terlebih dahulu dilekatkan pada PCB. Proses perekatan dapat dilakukan dengan bantuan laminator karena panas dan tekanannya lebih merata untuk hasil yang maksimal, jangan lebih dari 140 derajat celcius agar Dry Film tidak rusak. Sebelum dimasukkan ke dalam mesin laminator maka sebaiknya PCB yang akan dipasang dengan $d r y$ film disusun terlebih dahulu seperti pada gambar 4 .

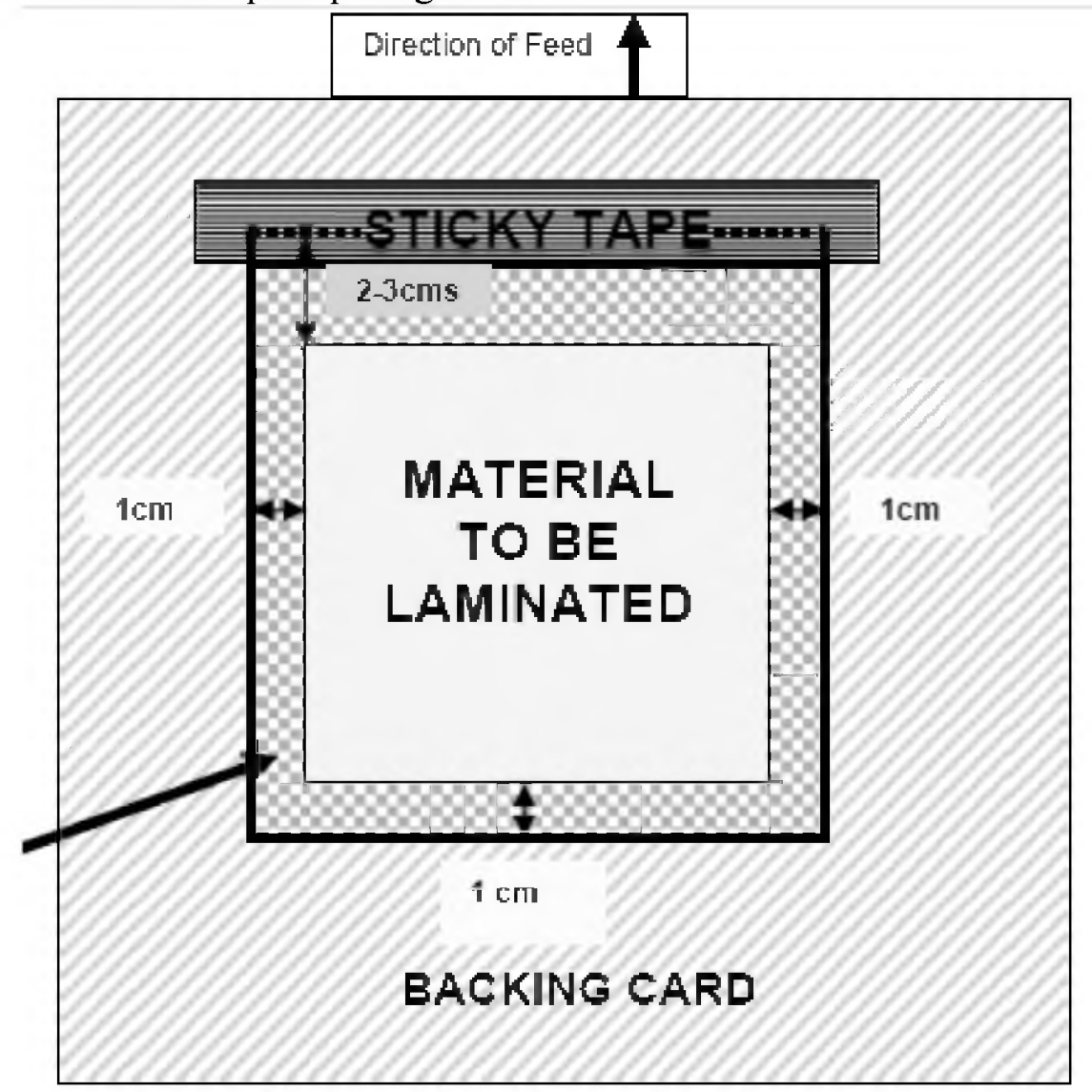

Gambar 4. Pemasanagn PCB pada mesin laminator

Pada gambar 4 menunjukkan tata cara dan ukuran pemasangan dry film pada PCB sebelum dimasukkan ke dalam mesin laminator.

Proses laminasi dengan laminator diperlihatkan pada gambar 5. 


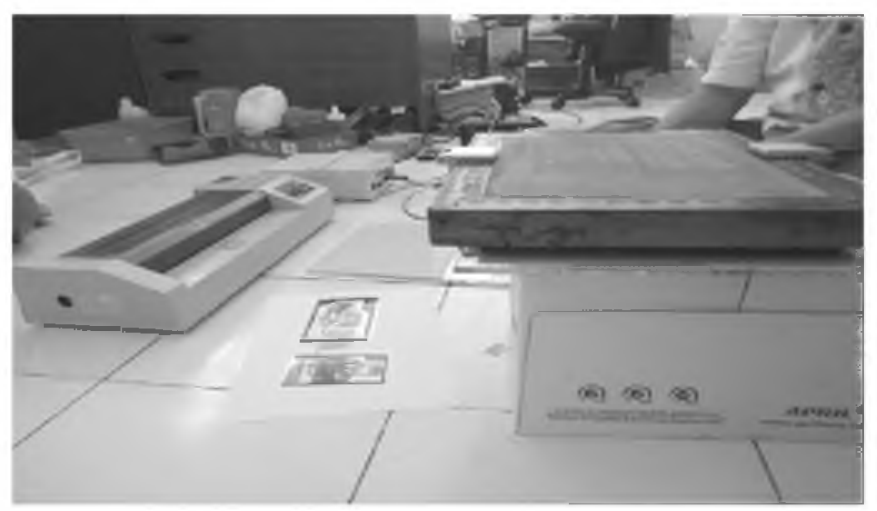

Gambar 5. Laminasi dengan mesin laminator

\subsubsection{Exposure (penyinaran)}

Tahap berikutnya adalah exposure (penyinaran), lampu yang digunakan lampu UV atau led UV, pada pengabdian ini akan digunakan led UV. Lekatkan film negatif sebagai artwork di PCB yang sudah dilaminasi dengan solasi, usahakan film melekat dengan baik (tidak mengambang) karena jika mengambang dry film tidak akan terexposure sempurna biasanya banyak jalur yang tidak nyambung, kalau penyinaran dari 1 arah (bawah saja) bagian PCB yang tidak/belum diexposure bisa ditindih dengan buku agar film benar-benar menempel. Untuk waktunya tergantung dari intensitas lampu, biasanya sekitar 60 detik. Bagian PCB yang terkena sinar UV akan berwarna ungu, sedangkan yang tertutup film tetap biru. Led UV yang digunakan untuk proses exposure terlihat pada gambar 6 dan proses penyinaran diperlihatkan pada gambar 7

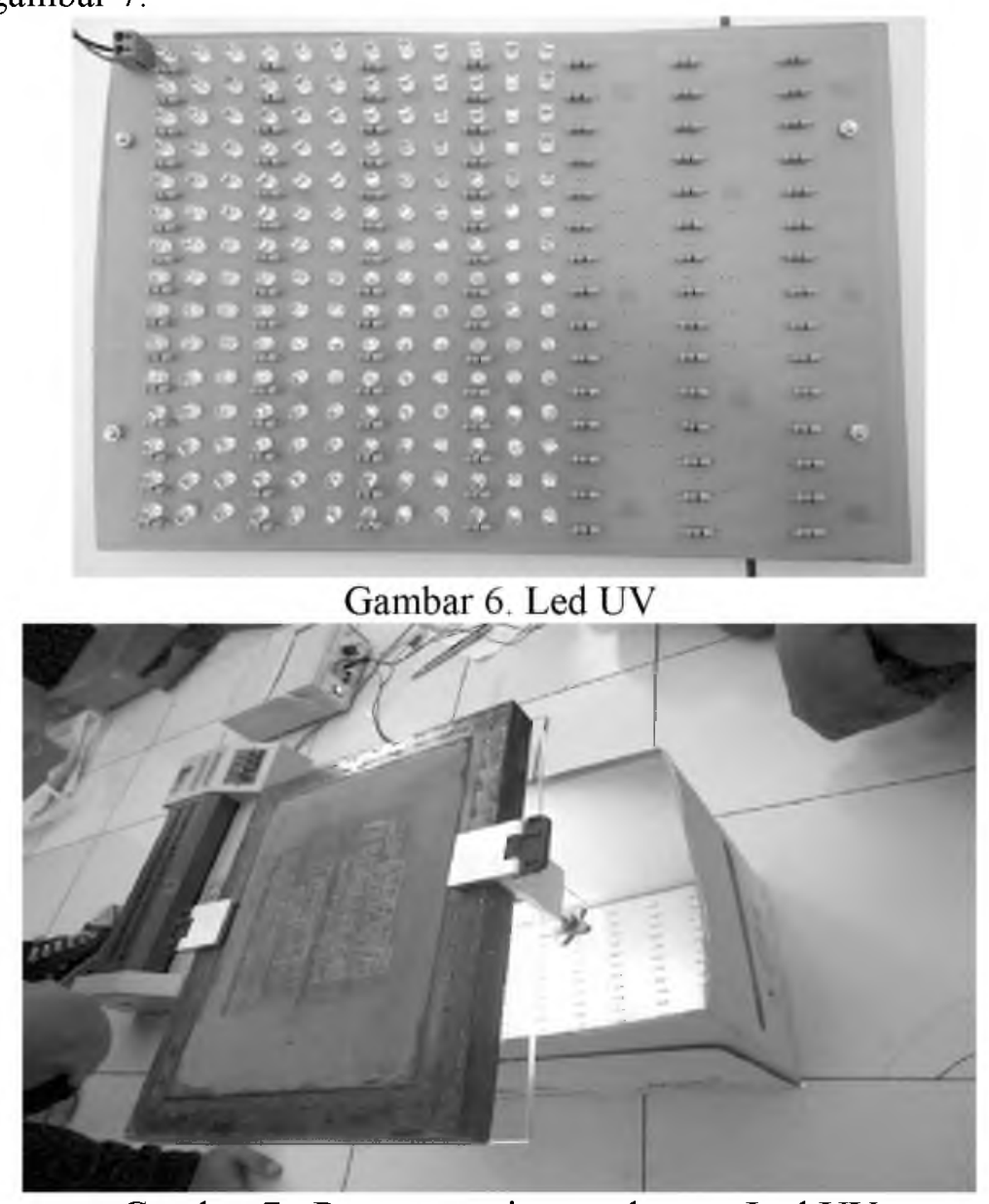

Gambar 7. Proses penyinaran dengan Led UV 


\subsubsection{Post Exposure Hold Time}

Setelah PCB di expose (disinari), kupas plastik bagian atas yang bening tapi jangan langsung di-developing, biarkan ditempat yang gelap selama minimal 15 menit agar jalur film (artwork) dapat tertranfer ke Dry Film dengan sempurna.

\subsubsection{Development (pengembangan)}

Bahan kimia yang digunakan pada proses development (pengembangan) ini adalah $\mathrm{NaOh}$ (soda api) dengan takaran disesuaikan dengan datasheet masing-masing dry film yang dipakai. Untuk hasil yang maksimal suhu air sebaiknya sekitar $31^{\circ} \mathrm{C}-35^{\circ} \mathrm{C}$.

Memasukkan PCB ke dalam air hangat yang sudah dicampur dengan soda api. Tunggu sampai Dry Film yang tidak terkena sinar larut, tinggal jalurnya saja, dapat dibantu dengan digosok secara perlahan menggunakan sikat halus, setelah bersih bilas dengan air bersih. Proses development diperlihatkan pada gambar 8. Hasil PCB yang telah melewati proses pengembangan diperlihatkan pada gambar 9 .

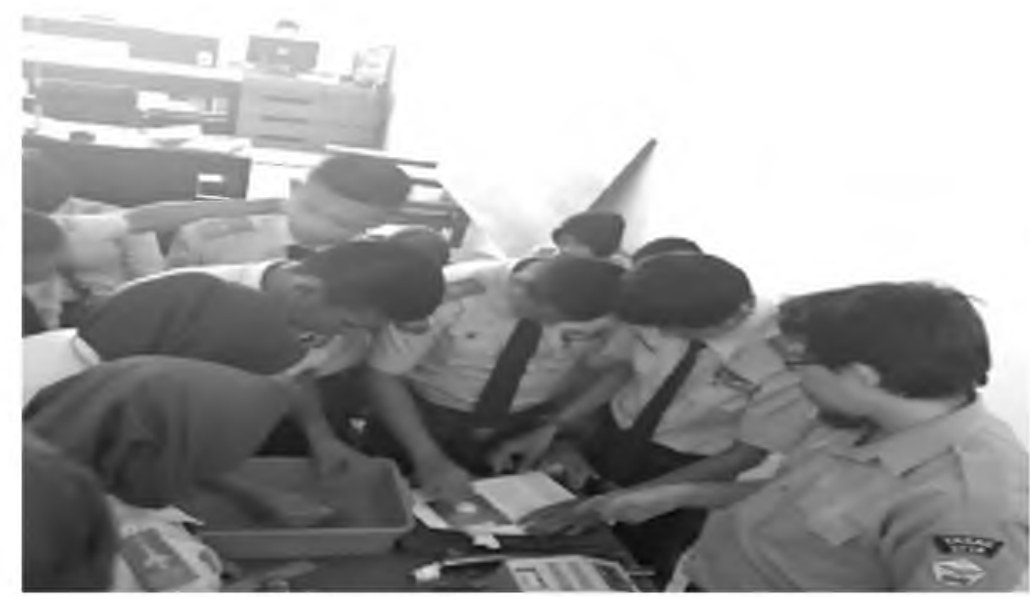

Gambar 8. Proses pengembangan

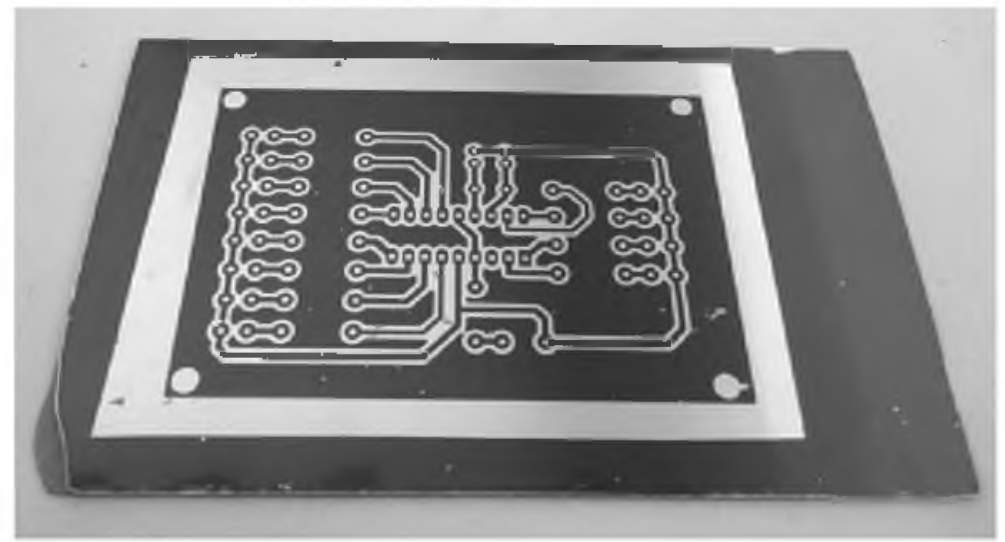

Gambar 9. PCB setelah proses pengembangan

\subsubsection{Pre Etch Drying}

PCB yang sudah di developing sebaiknya dikeringkan dulu menggunakan hair dryer, bisa juga dijemur di sinar matahari langsung sekitar +5 menit agar lebih kuat jadi jalur tidak rusak saat dietching. 


\subsubsection{Etching}

Alat yang dipakai bisa terbuat dari bahan plastik tebal atau kaca, hampir sama dengan alat developing hanya saja dimensi lebarnya lebih kecil. Etching jadi lebih cepat dan efisien karena bisa memuat beberapa PCB sekaligus. Proses etching berguna untuk menghilangkan tembaga pada PCB yang tidak tertutup Dry Film (bukan jalur). Biasanya menggunakan Ferrit Chloride $(\mathrm{FeCl})$ tapi bisa juga menggunakan Ammonium Persulfate dengan komposisi sebagai berikut $75 \%$ air ; $12,5 \% \mathrm{H} 2 \mathrm{O} 2$ dan $12,5 \% \mathrm{HCl}$, setelah selesai bersihkan dengan air bersih. Proses etching diperlihatkan pada gambar 10 .

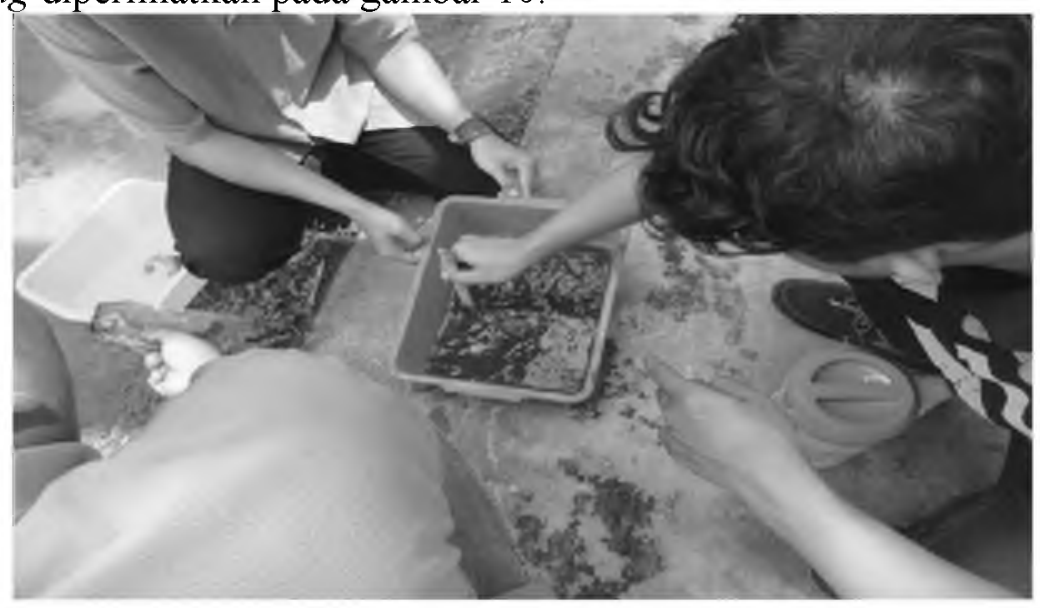

Gambar 10. Proses Etching

\subsubsection{Stripping}

Ditahap ini PCB yang selesai di-etching akan dihilangkan Dry Film-nya, larutan yang dipakai air dicampur dengan $\mathrm{NaOH}$ (soda api) dengan komposisi yang lebih banyak dari developing, semakin banyak soda api akan semakin cepat Dry Film terkelupas. Tapi untuk bahan FR2 (pertinak) jangan terlalu lama direndam karena warna PCB bisa berubah. Proses stripping diperlihatkan pada gambar 11

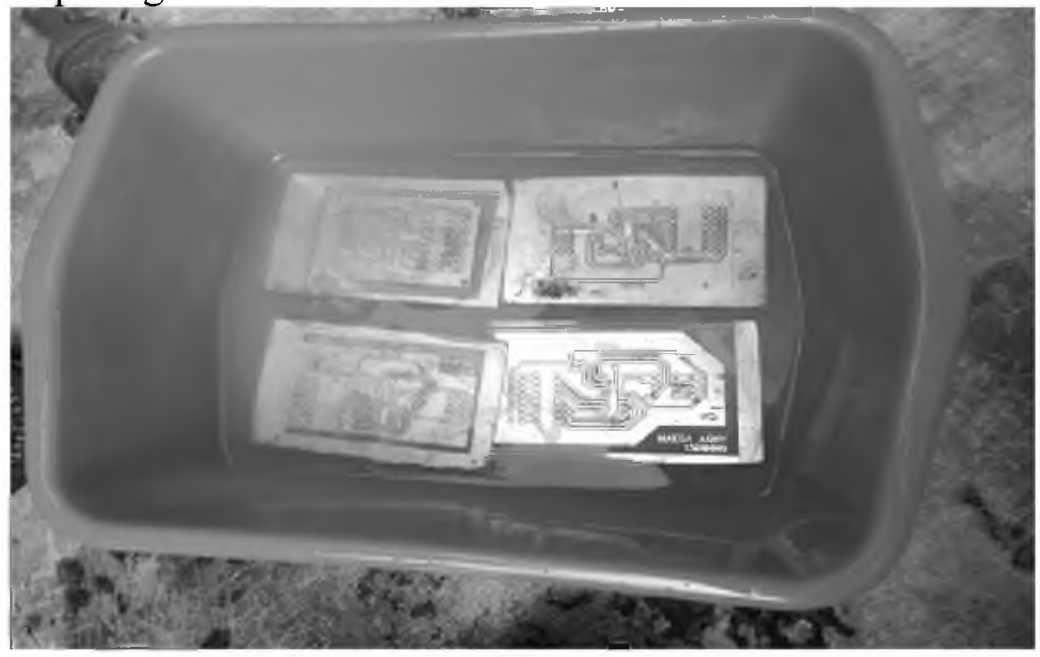

Gambar 11. Proses Stripping

PCB yang telah melalui proses stripping selanjutnya dibersihkan dengan cara dibilas menggunakan air.

\subsubsection{Finishing}

Proses finishing meliputi berbagai proses yaitu : proses pengeboran PCB, Silver Coating, Tin Plating yang biasanya dilanjutkan dengan proses Masking + Lettering. Masking 
berfungsi untuk memudahkan dalam proses solder dan melindungi pcb supaya lebih awet. Lettering memudahkan dalam pemasangan posisi komponen dan untuk mengetahui nilai atau spesifikasi komponen. Lettering biasanya berwarna putih dan menggunakan tehnik sablon dalam pengerjaannya. Masking umumnya berwarna hijau dan biru bisa menggunakan tehnik sablon tapi ada juga yang memakai Dry Film Soldermask dengan tehnik image photo transfer. Proses pengeboran PCB diperlihatkan pada gambar 12

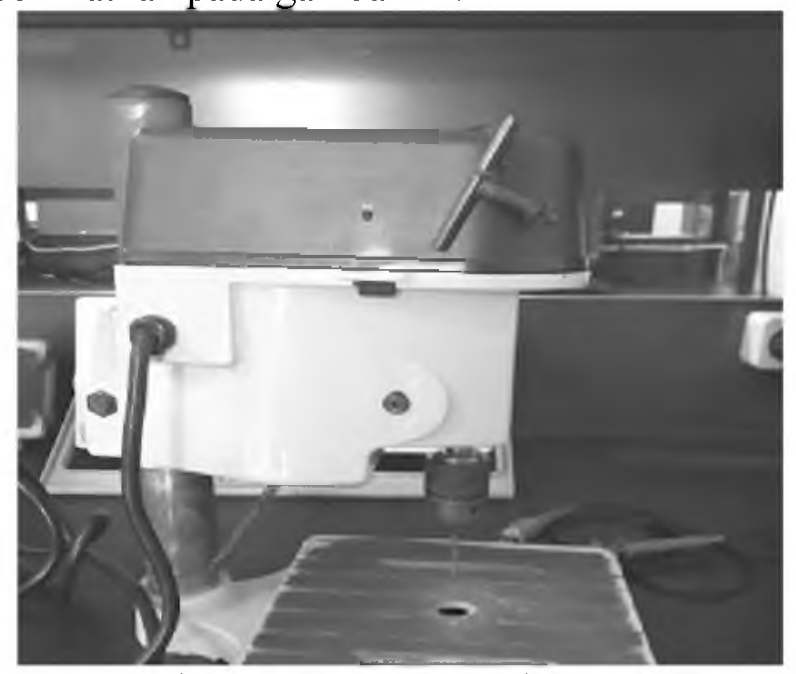

Gambar 12. Proses pengeboran PCB

\section{Hasil dan Pembahasan}

Gambar Layout PCB dari skema rangkaian dibuat menggunakan perangkat lunak DIP TRACE di diperlihatkan pada gambar 13.

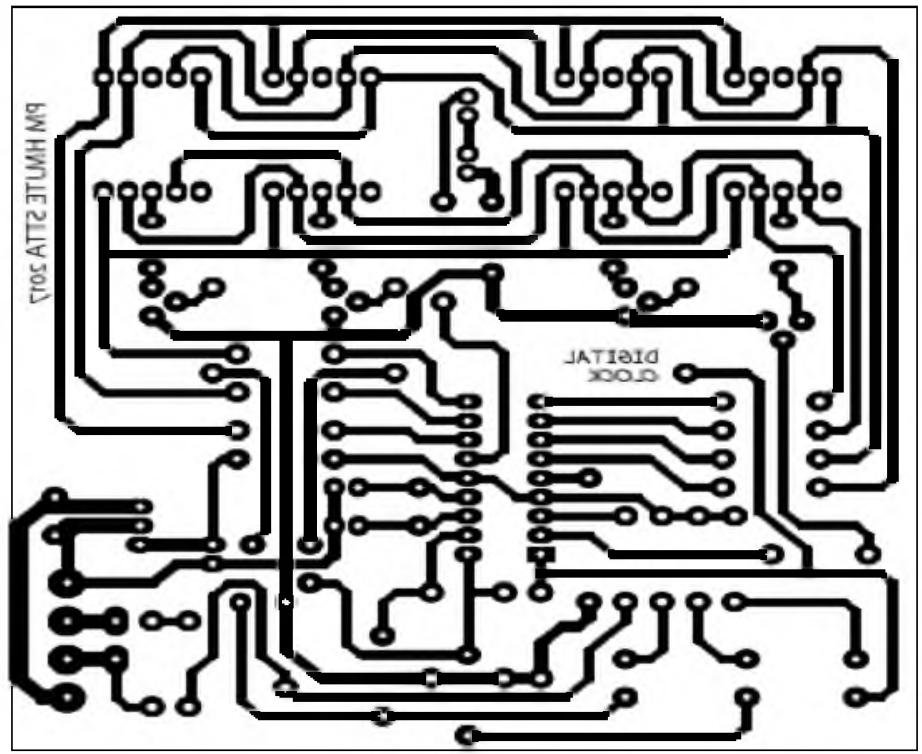

Gambar 13. Layout PCB hasil rancangan

Dry Film Photoresist memerlukan hasil print-out negatif, sehingga layout hasil rancangan pada gambar 13 harus dicetak negatif. Hasil cetak negatif layout hasil rancangan diperlihatkan pada gambar 14 . 


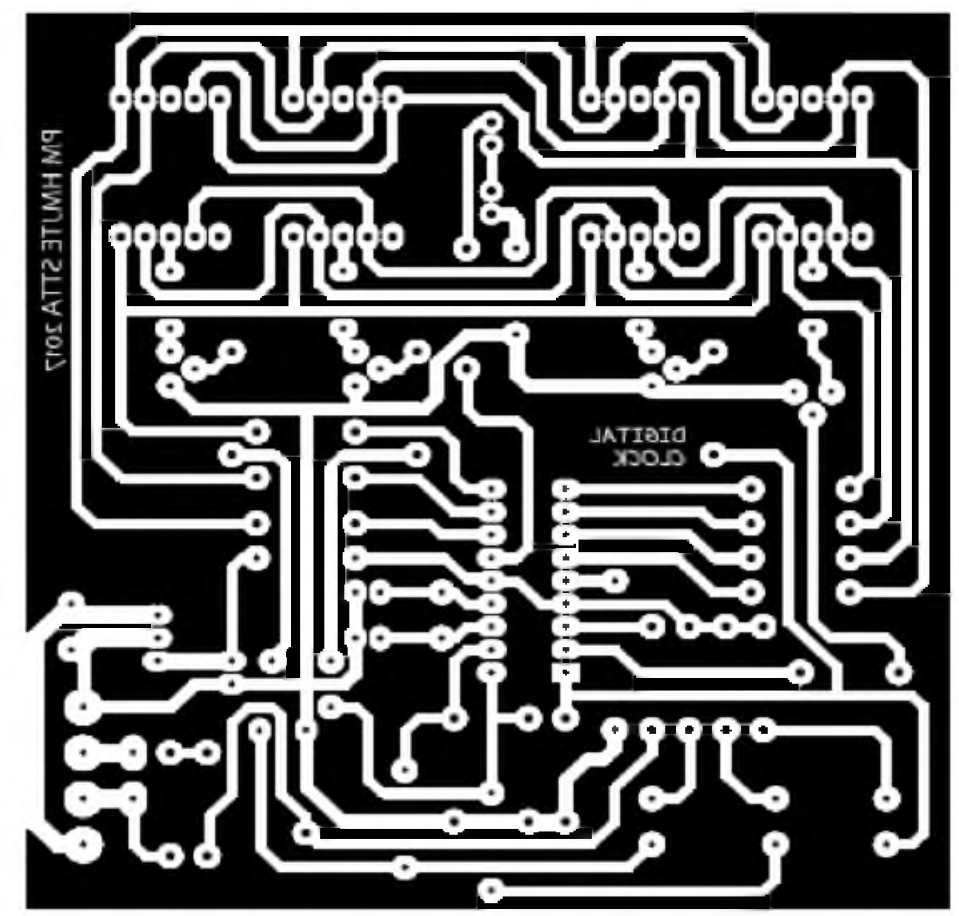

Gambar 14. Layout PCB negatif

Hasil PCB yang telah selesai dan siap untuk proses finishing diperlihatkan pada gambar 15.

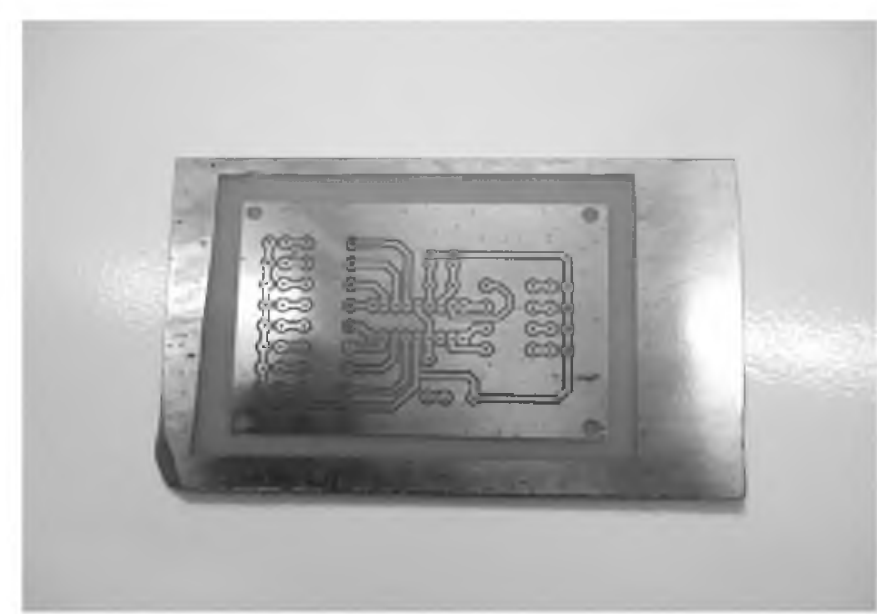

Gambar 15. PCB yang sudah jadi dan siap untuk proses finishing

\section{Kesimpulan}

Dari uraian yang telah dijabarkan di depan maka dapat diambil beberapa kesimpulan sebagai berikut :

1. Program pelatihan telah dapat mencapai sasaran sesuai dengan target yang telah ditentukan yaitu siswa mampu untuk menggambar skematik dan membuat layout PCB menggunakan software DIP TRACE dan siswa mampu melakukan transfer dari gambar loyout PCB ke PCB menggunakan teknologi Dry Film Photoresist.

2. Keterlibatan siswa sebagai peserta pengabdian sangat mendukung terselenggaranya program pengabdian kepada Masyarakat ini.

3. Keterlibatan siswa dapat meningkatkan kemampuan pengetahuan soft skill siswa. 


\section{Daftar Pustaka}

[1] Dermawan D., 2016, "Pembuatan Printed Circuit Board (PCB) dengan teknologi Dry Film Photoresist bagi Himpunan Mahasiswa Jurusan Teknik Elektro (HMJTE) Sekolah Tinggi teknologi Adisutjipto (STTA) Yogyakarta", laporan pengabdian masyarakat tahun 2016.

[2] .........., "How to laminate the dry film photoresist", Mega Electronics Ltd, Mega house, Grip Industrial Estate, Linton Cambridge, England. http://www.megauk.com

[3] ........., 2011, "Cetak PCB menggunakan dry film photoresist", http://www.maxtronpersada.com/

[4] .........,2016, "Dip Trace schematic and PCB design software tutorial", http://www.diptrace.com

[5] ..........., "UV Led Exposure Box", http://www.CarbonFrog.com 